\title{
Oficina educativa sobre aleitamento materno para gestantes de uma unidade saúde da família
}

\author{
Educational workshop on breastfeeding for pregnant women at a family health unit \\ Taller educativo sobre lactancia materna para embarazadas en una unidad de salud \\ familiar
}

Priscilla Shirley Siniak dos Anjos Modes ${ }^{1 *}$, Maria Aparecida Munhoz Gaíva², Ariane Liamara Brito Sala Braun ${ }^{3}$, Vanda Patricia da Silva Santos ${ }^{1}$.

\section{RESUMO}

Objetivo: Analisar os efeitos de uma oficina educativa sobre aleitamento materno para gestantes acompanhadas em uma unidade saúde da família. Métodos: Trata-se de uma pesquisa de intervenção com a participação de 20 gestantes. A intervenção educativa foi desenvolvida por meio das seguintes etapas: identificação do problema; organização da oficina; divulgação; confecção e entrega de uma tecnologia educativa sobre a temática; oficina educativa; reforço da intervenção educativa e avaliação por meio de um pré e pós teste imediato e tardio sobre a temática trabalhada na oficina. Os resultados foram analisados de forma descritiva. Resultados: Após a intervenção, observou-se um acréscimo de acertos nas respostas das gestantes e ampliação do conhecimento das mesmas sobre o início do aleitamento materno na primeira hora de vida, causas e prevenção dos problemas mamários. Os benefícios do aleitamento materno para as nutrizes necessitam ser reforçados nos atendimentos em saúde, assim como os cuidados com ordenha, armazenamento e administração do leite. Conclusão: A oficina educativa auxiliou a ampliar o conhecimento das gestantes participantes e poderá contribuir para sua autonomia e poder decisório sobre a prática da amamentação.

Palavras-chave: Gestantes, Aleitamento materno, Educação em saúde.

\begin{abstract}
Objective: To analyze the effects of an educational workshop on breastfeeding for pregnant women accompanied at a family health unit. Methods: This is an intervention research with the participation of 20 pregnant women. The educational intervention was developed through the following steps: problem identification; organization of the workshop; disclosure; making and delivering educational technology on the subject; educational workshop; reinforcement of educational intervention and evaluation through an immediate and late pre and post test on the theme worked in the workshop. The results were analyzed descriptively. Results: After the intervention, there was an increase in correct answers in the responses of pregnant women and an increase in their knowledge about the beginning of breastfeeding in the first hour of life, causes and prevention of breast problems. The benefits of breastfeeding for nursing mothers need to be reinforced in health care, as well as care with milking, storage and administration of milk. Conclusion: The educational workshop helped to expand the knowledge of the participating pregnant women and may contribute to their autonomy and decision-making power on the practice of breastfeeding.
\end{abstract}

Keywords: Pregnant women, Breastfeeding, Health education.

\footnotetext{
${ }^{1}$ Universidade Federal de Mato Grosso (UFMT), Sinop - MT. *E-mail: priscilladosanjos@yahoo.com.br 2Universidade Federal de Mato Grosso (UFMT), Cuiabá - MT.

${ }^{3}$ Universidade de Cuiabá (UNIC), Primavera do Leste - MT.
} 


\section{RESUMEN}

Objetivo: Analizar los efectos de un taller educativo sobre lactancia materna para mujeres embarazadas acompañado en una unidad de salud familiar. Métodos: Esta es una investigación de intervención con la participación de 20 mujeres embarazadas. La intervención educativa se desarrolló a través de los siguientes pasos: identificación del problema; organización del taller; divulgar; hacer y entregar tecnología educativa sobre el tema; taller educativo; refuerzo de la intervención y evaluación educativas a través de una prueba previa y posterior inmediata y tardía sobre el tema trabajado en el taller. Los resultados fueron analizados descriptivamente. Resultados: Después de la intervención, hubo un aumento en las respuestas correctas en las respuestas de las mujeres embarazadas y un aumento en su conocimiento sobre el comienzo de la lactancia materna en la primera hora de vida, las causas y la prevención de problemas en los senos. Los beneficios de la lactancia materna para las madres lactantes deben reforzarse en el cuidado de la salud, así como en el cuidado con el ordeño, el almacenamiento y la administración de la leche. Conclusión: El taller educativo ayudó a ampliar el conocimiento de las mujeres embarazadas participantes y puede contribuir a su autonomía y poder de decisión sobre la práctica de la lactancia materna.

Palabras clave: Mujeres embarazadas, Lactancia materna, Educación sanitaria.

\section{INTRODUÇÃO}

O aleitamento materno representa uma experiência fundamental para o desenvolvimento motor, cognitivo, psicossocial e nutricional da criança. Considerando estes e outros inúmeros benefícios da amamentação, a Organização Mundial da Saúde (OMS), o Fundo das Nações Unidas para a Infância (UNICEF) e o Ministério da Saúde do Brasil recomendam que a nutriz amamente seus filhos, exclusivamente com leite materno, nos primeiros seis meses de vida e de forma complementar até os dois anos (MINISTÉRIO DA SAÚDE, 2015a).

Sua relevância no cenário da saúde infantil se dá porque o leite materno possui componentes básicos para a manutenção da vida das crianças, auxiliando na redução da mortalidade na infância (FERREIRA CKM, et al., 2017; SANTOS VR, et al., 2016), por meio dos nutrientes que auxiliam no crescimento e desenvolvimento infantil saudável, criação de vínculo, afeto e proteção materna (MINISTÉRIO DA SAÚDE, 2015a) e fortalecimento do sistema imunológico do neonato, evitando infecções, diarreia, dentre outros agravos (SANTOS GCP, et al., 2017).

Diante dos benefícios do leite materno, o incentivo e o apoio ao aleitamento materno devem ser contínuos para a promoção de conhecimento adequado, manutenção e motivação para sua prática efetiva. Para tal, os profissionais de saúde devem identificar e esclarecer as dúvidas e dificuldades relacionadas à amamentação, contribuindo para uma assistência que apoie a mulher para que ela alcance o êxito desejável de amamentar (VARGAS GS, et al., 2016).

Nesse sentido, a prática educativa é uma ferramenta de transmissão de conhecimento para estabelecimento de relação crítica-reflexiva entre os envolvidos (QUENTAL LLC, et al., 2017), que pode ser desenvolvida pelo enfermeiro na atenção primária à saúde, com o objetivo de auxiliar na prevenção de doenças, favorecer mudanças de comportamento do indivíduo/coletividade, incentivar o autocuidado, conscientizar sobre a saúde individual (BONFIM ES, et al., 2017; QUENTAL LLC, et al., 2017) e, consequentemente contribuir para o incentivo da prática do aleitamento materno (VIEIRA F, et al., 2016).

A educação em saúde é uma estratégia fundamental para a promoção da saúde e autonomia dos sujeitos, no contexto da atenção primária à saúde, em especial, pelos profissionais que atuam nas Unidades Saúde da Família (USF).

Nesse sentido, durante o período gravídico puerperal, as ações de educação em saúde tornam-se aliadas para a proteção e promoção da saúde da mulher e neonato, ferramenta esta que o enfermeiro pode fazer uso, seja por meio de grupo de gestantes, de puérperas, em sala de espera, consultas individuais de pré-natal (RICCI APA, et al., 2019) ou de puericultura. 
Estes espaços educativos servem para sanar dúvidas, fortalecer o vínculo entre o binômio mãe e bebê, dar condições de segurança para o manejo do aleitamento materno, além de oportunizar o acesso ao conhecimento sobre os benefícios dessa prática para ambos.

Assim, justifica-se o desenvolvimento de intervenções educativas, especificamente por meio de oficinas sobre o aleitamento materno nos cenários das USF. Esse tipo de atividade desenvolvida pelo profissional de saúde dá à mulher maior confiança em sua capacidade para amamentar o filho, diminuindo ansiedades e auxiliando na manutenção do aleitamento materno. Sendo assim, este estudo teve como objetivo analisar os efeitos de uma oficina educativa sobre aleitamento materno para gestantes acompanhadas em uma unidade saúde da família (USF).

\section{MÉTODOS}

Trata-se de uma pesquisa de intervenção, do tipo antes e depois, com um componente avaliativo sobre o conhecimento de gestantes sobre o aleitamento materno, antes e após a aplicação de uma oficina educativa sobre o tema. As pesquisas de intervenção com foco na promoção da saúde constituem-se em uma prática importante para facilitar a reflexão crítica do pesquisado, favorecer a autonomia das pessoas envolvidas e proporcionar momentos de experiências efetivas para o aprendizado (MENDES R, et al., 2016).

O estudo foi realizado em uma USF localizada no município de Sinop, MT, escolhida por ser campo de prática dos alunos de graduação da Universidade Federal de Mato Grosso (UFMT) e do desenvolvimento de projeto de extensão de atenção à saúde da mulher e do neonato.

A amostra do estudo foi por conveniência, composta por 20 gestantes em diferentes períodos gestacionais e em acompanhamento pré-natal na referida unidade de saúde. Destas, 12 gestantes participaram de todas as etapas (pré-teste, pós teste imediato e tardio) e 8 apenas da primeira etapa (pré e pós-teste imediato). A ideia inicial era realizar apenas uma oficina com todas as gestantes cadastradas na unidade de saúde, que na ocasião era composta de 50 mulheres, porém, como não houve uma adesão representativa na primeira reunião, optou-se por conduzir a oficina em dois momentos, para que houvesse um número maior de participantes.

As etapas para a realização da intervenção educativa foram: 1) identificação do problema na realidade estudada (baixos índices de aleitamento materno e problemas mamários), que foram detectados nas consultas de enfermagem às puérperas e recém-nascidos; 2) organização da atividade educativa (planejamento); 3) divulgação da atividade, 4) aplicação da intervenção; 5) confecção e entrega de uma tecnologia educativa (folder) sobre a temática, 6) reforço dos temas abordados na intervenção; e 7) avaliação do efeito da intervenção (CORDONI JUNIOR L, 2013). A coleta de dados durou de março a junho de 2018.

O objetivo da oficina educativa foi promover reflexão e conscientização das gestantes sobre o aleitamento materno. A mobilização e a sensibilização do público-alvo foram realizadas pelos agentes comunitários de saúde (ACS) da USF, que entregaram os convites individuais com antecedência de 30 dias e reforçaram o convite por meio de ligação telefônica próximo da data da intervenção. Além disso, foi colocado um cartaz na USF para divulgação da atividade e utilizado um aplicativo de celular para enviar mensagens às gestantes que participavam das reuniões mensais do projeto de extensão, a fim de lembrar a data e horário da oficina. A ação contou também com apoio dos médicos e da enfermeira da unidade que reforçaram o convite pessoalmente durante as consultas de pré-natal.

A intervenção foi efetuada por meio de duas oficinas educativas que ocorreram em março e abril de 2018, intitulada "Dicas de sucesso para uma amamentação eficaz", que abordou os seguintes temas: Anatomia da mama; Classificações e fases do leite materno; Benefícios da amamentação para mãe e bebê; Posicionamento adequado para amamentar; Técnica correta da pega, ordenha, armazenamento e administração do leite materno; Causas e prevenção de mastite, ingurgitamento mamário e fissura mamilar. Tais temáticas foram trabalhadas em forma de jogos educativos que visavam o envolvimento das participantes e a reflexão. 
Os dois encontros da oficina tiveram duração média de três horas cada um e foram desenvolvidos na seguinte sequência: 1) Pré-teste; 2) Dinâmica "quebra-gelo interativa" em que foi entregue às gestantes massa de modelar para que pudessem moldar uma mama com as alterações anatômicas e fisiológicas que elas percebiam em si mesmas; 3) Dinâmica "Fala sério ou com certeza", que abordou a classificação do leite materno e suas fases; 4) Dinâmica "Semáforo da Amamentação", que enfocou as causas e a prevenção da mastite, ingurgitamento mamário e fissuras mamilar; 5) Dinâmica "Bingo da Amamentação", que trabalhou os benefícios da amamentação para mãe e bebê; 6) Demonstração das técnicas de amamentação e administração do leite materno com bonecos e materiais ilustrativos; 7) Entrega do folder com dicas para uma amamentação eficaz; e 8) Pós-teste.

Foi entregue às gestantes participantes o mesmo formulário semiestruturado nos três diferentes momentos de aplicações dos testes (pré-teste, pós-teste imediato e tardio), norteados pelo mesmo roteiro, que foi elaborado pelas pesquisadoras com base nos assuntos trabalhados na intervenção educativa, contendo 11 questões fechadas e 7 abertas. Ao final da atividade educativa as gestantes receberam um folder com informações sobre o que havia sido abordado. Ao término das oficinas, as pesquisadoras se colocaram à disposição das gestantes para sanar as dúvidas e dar apoio durante o processo de amamentação, via mensagem de celular.

Os efeitos da intervenção foram avaliados por meio do pós-teste em duas etapas. Na primeira etapa, o instrumento foi aplicado imediatamente após a intervenção (pós-teste imediato) e, na segunda, 30 dias após a intervenção (pós-teste tardio), na residência das gestantes, utilizando o mesmo formulário. O pós-teste imediato teve por finalidade avaliar o efeito imediato da intervenção sobre o conhecimento das gestantes a respeito do aleitamento materno $(\mathrm{AM})$ e, o pós-teste tardio visou avaliar se o efeito da intervenção se sustentou sobre o conhecimento das gestantes, garantindo a sustentabilidade dos saberes.

O conhecimento das gestantes sobre AM foi avaliado por meio de questões objetivas e classificado como insuficiente, regular, bom e ótimo, convertidas em percentuais, da seguinte forma: insuficiente (até $24 \%$ de acertos), regular (25\% a $49 \%$ de acertos), bom (50\% a $74 \%$ de acertos) e ótimo $(75 \%$ a $100 \%$ de acertos) (BLANCO E SILVA F, et al., 2018).

Os dados foram analisados descritivamente e apresentados em forma de tabelas e gráficos. A pesquisa foi aprovada pelo Comitê de Ética em Pesquisa, sob o parecer № 2.541 .773 , seguindo a Resolução 466/2012 (CONSELHO NACIONAL DE SAÚDE, 2012). Todas as participantes assinaram o Termo de Consentimento Livre e Esclarecido em duas vias, ficando com uma delas, e os responsáveis pelas gestantes adolescentes autorizaram sua participação na pesquisa e as mesmas assinaram o termo de assentimento livre e esclarecido.

\section{RESULTADOS}

As 20 gestantes participantes estavam na faixa etária de 16 a 40 anos de idade, com predomínio entre 21 a 24 anos (9/45\%). Maior proporção de participantes declarou ser casada (12/60\%), metade (10/50\%) informou ter ocupação remunerada e uma parcela possuir ensino médio completo (8/40\%). Quanto aos aspectos obstétricos, observou-se que $60 \%$ (12) eram multigestas, com parto vaginal (8/66,7\%) e 20\% (4) já haviam tido aborto em gestação anterior.

$\mathrm{Na}$ questão que abordou o momento ideal de se iniciar a amamentação, no pré-teste somente duas participantes $(2 / 10 \%)$ assinalaram corretamente a resposta, apresentando um conhecimento considerado insuficiente. No pós-teste imediato, a maioria (19/95\%), respondeu corretamente, evidenciado melhora na compreensão das participantes. No pós- teste tardio foram assinaladas 11 respostas corretas (92\%). Ambos os pós testes foram classificados como ótimo.

Quanto a avaliação do conhecimento sobre a duração da amamentação exclusiva, no pré-teste 13 (65\%) responderam corretamente, demonstrando um bom conhecimento. No pós-teste imediato o número de respostas corretas aumentou para 17 (85\%), e no pós-teste tardio, o conhecimento foi classificado como ótimo (10/83,3\%). Quanto ao conhecimento das participantes em ofertar outros líquidos antes dos seis meses de idade da criança, o conhecimento partiu de bom e manteve-se ótimo (Gráfico 1). 
Gráfico 1 - Conhecimento das participantes sobre o início e duração do Aleitamento Materno Exclusivo (AME) e introdução de outros líquidos durante essa prática, no pré-teste, pós-teste imediato e pós-teste tardio, $\mathrm{n}=20$. Sinop $-\mathrm{MT}, 2018$.

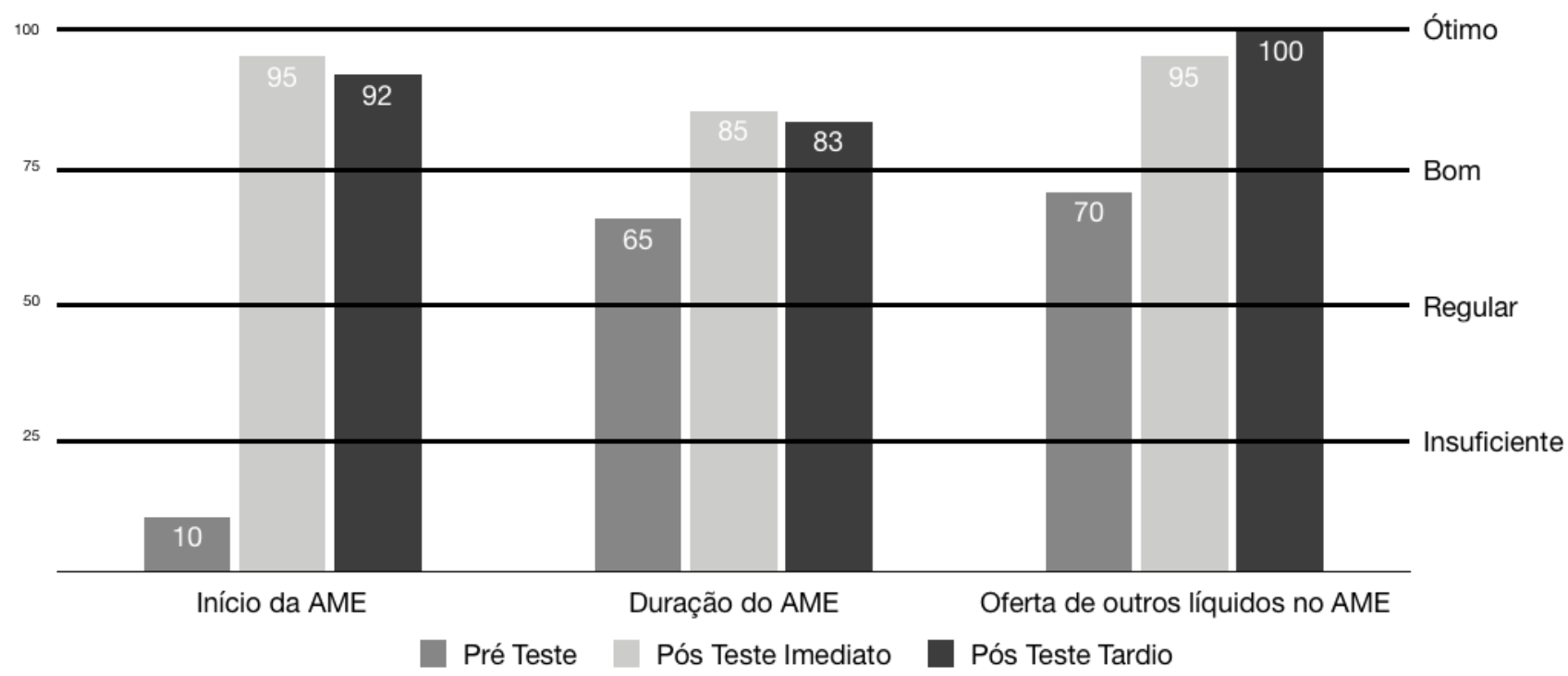

Fonte: Modes PSSA, et al., 2018.

Ao ser analisado o conhecimento das participantes sobre a posição e pega adequadas da criança durante a amamentação, observou-se que as gestantes apresentaram conhecimento insuficiente em quase todos os aspectos no pré-teste. No pós-teste imediato, as gestantes tiveram conhecimento regular na maioria dos itens e no pós-teste tardio, alcançaram conhecimento bom e ótimo (Gráfico 2).

Gráfico 2 - Conhecimento das participantes sobre o posicionamento e pega corretos da criança durante a amamentação, no pré-teste, pós-teste imediato e pós-teste tardio, n=20. Sinop - MT, 2018.

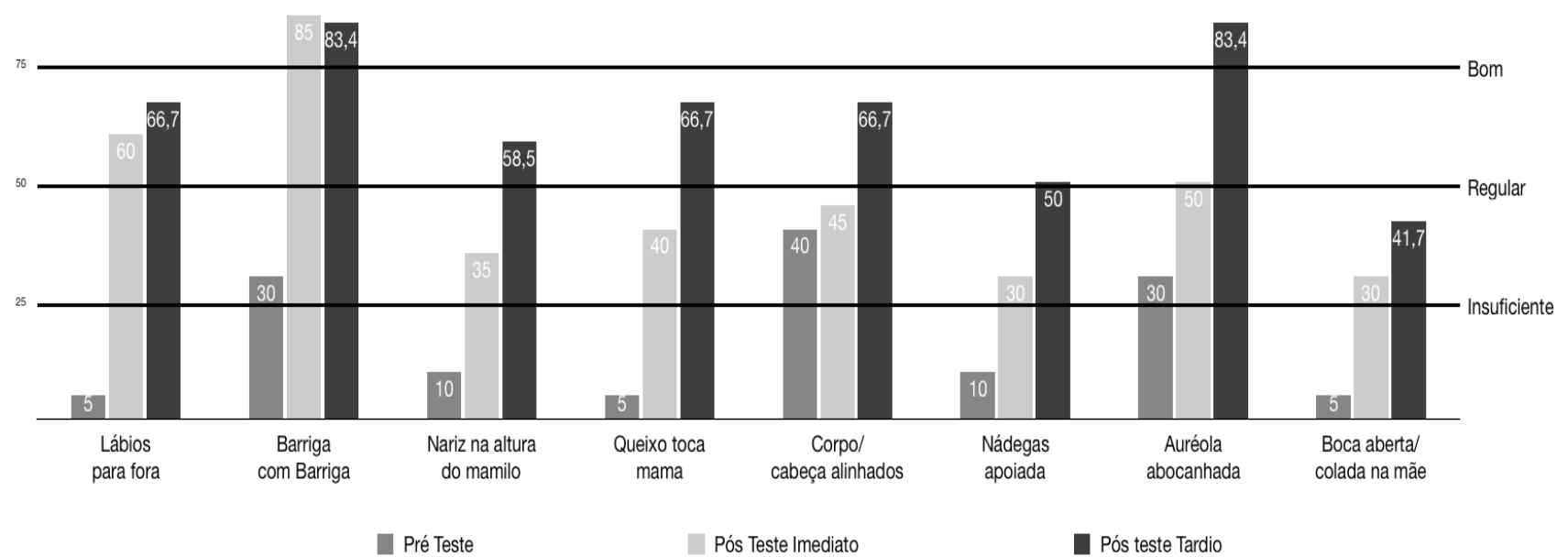

Fonte: Modes PSSA, et al., 2018.

No que se refere as manifestações do ingurgitamento mamário, todas as gestantes demonstraram conhecimento insuficiente no pré-teste sobre os sintomas de aumento das mamas e obstrução da saída do leite, e conhecimento regular sobre leite retido na mama. No pós-teste imediato alcançaram conhecimento bom a ótimo e no pós-teste tardio, conhecimento bom e ótimo.

No que se refere às medidas preventivas para o ingurgitamento mamário, as gestantes apresentaram conhecimento insuficiente e regular no pré-teste, e no pós-teste imediato conhecimento bom. No pós-teste tardio, conhecimento entre bom e ótimo nas quatro questões abordadas (Gráfico 3). 
Gráfico 3 - Conhecimento das participantes sobre a prevenção do ingurgitamento mamário no pré-teste, pós-teste imediato e pós-teste tardio, $n=20$. Sinop - MT, 2018.

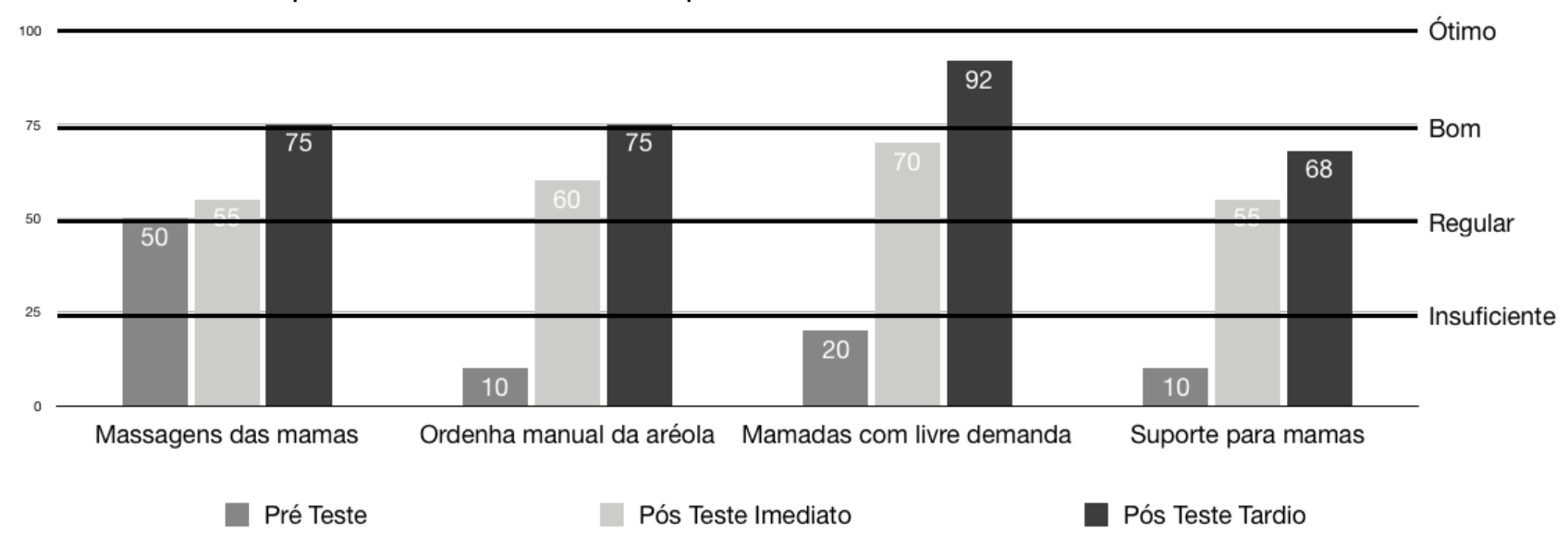

Fonte: Modes PSSA, et al., 2018.

Nas questões sobre a ordenha, armazenamento e administração do leite materno, as gestantes apresentaram conhecimento insuficiente a regular no pré-teste, com ampliação do conhecimento no pósteste imediata e no tardio (Gráfico 4).

Gráfico 4 - Conhecimento das gestantes sobre a ordenha, armazenamento, e administração do leite materno no pré-teste, pós-teste imediato e tardio, n=20. Sinop - MT, 2018.

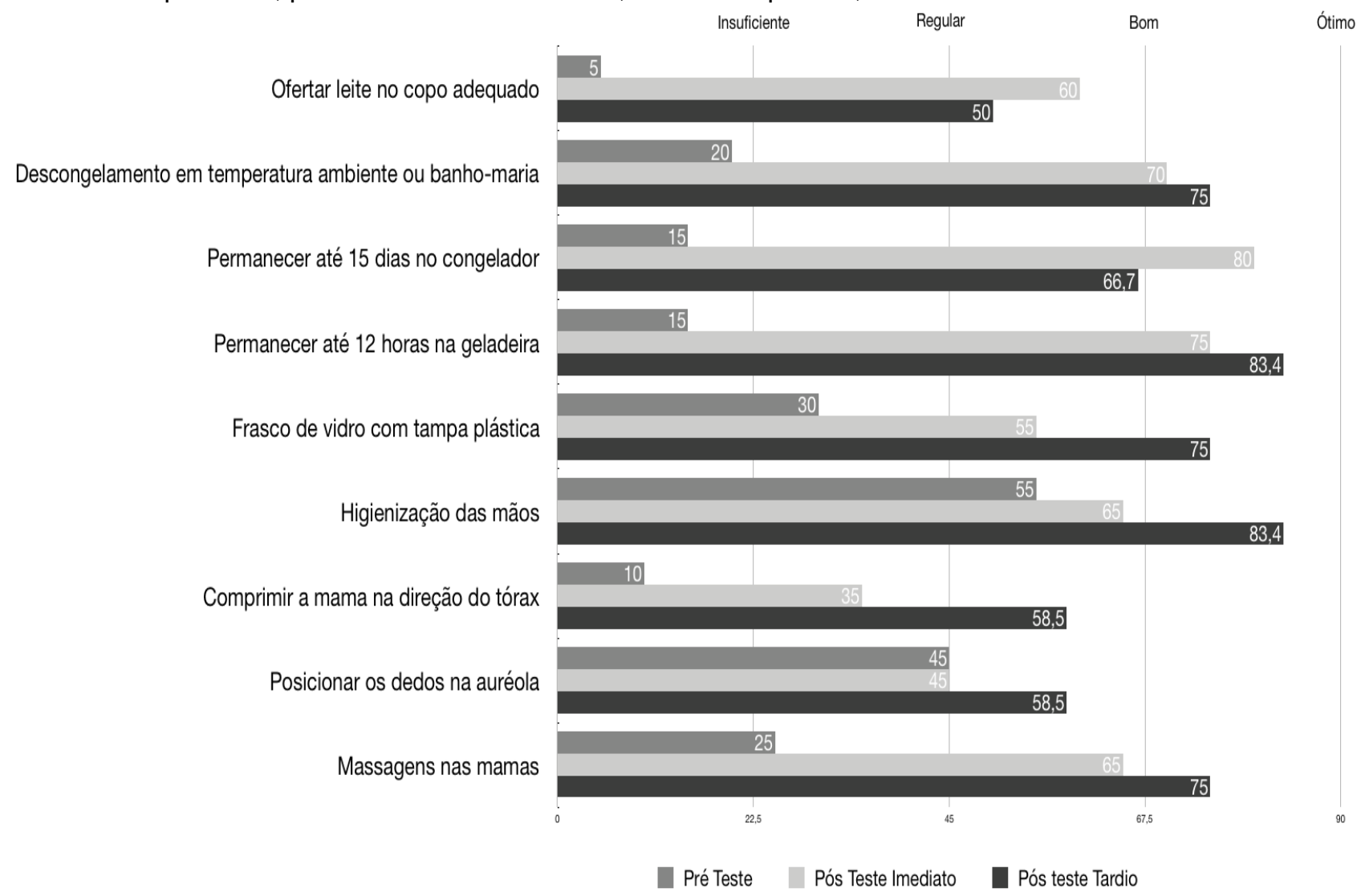

Fonte: Modes PSSA, et al., 2018.

Quanto aos benefícios da amamentação ao binômio mãe-bebê, as participantes demonstraram conhecimento prévio regular sobre a maioria dos quesitos e insuficiente sobre o benefício da contracepção e a prevenção da osteoporose. No pós-teste imediato melhoraram o conhecimento, mas ainda mantiveram conhecimento regular sobre a contracepção e prevenção da osteoporose (Gráfico 5). 
Gráfico 5 - Conhecimento das participantes gestantes no pré-teste, pós-teste imediato e tardio sobre os benefícios do leite materno para a mãe, $n=20(\%)$. Sinop - MT, 2018.

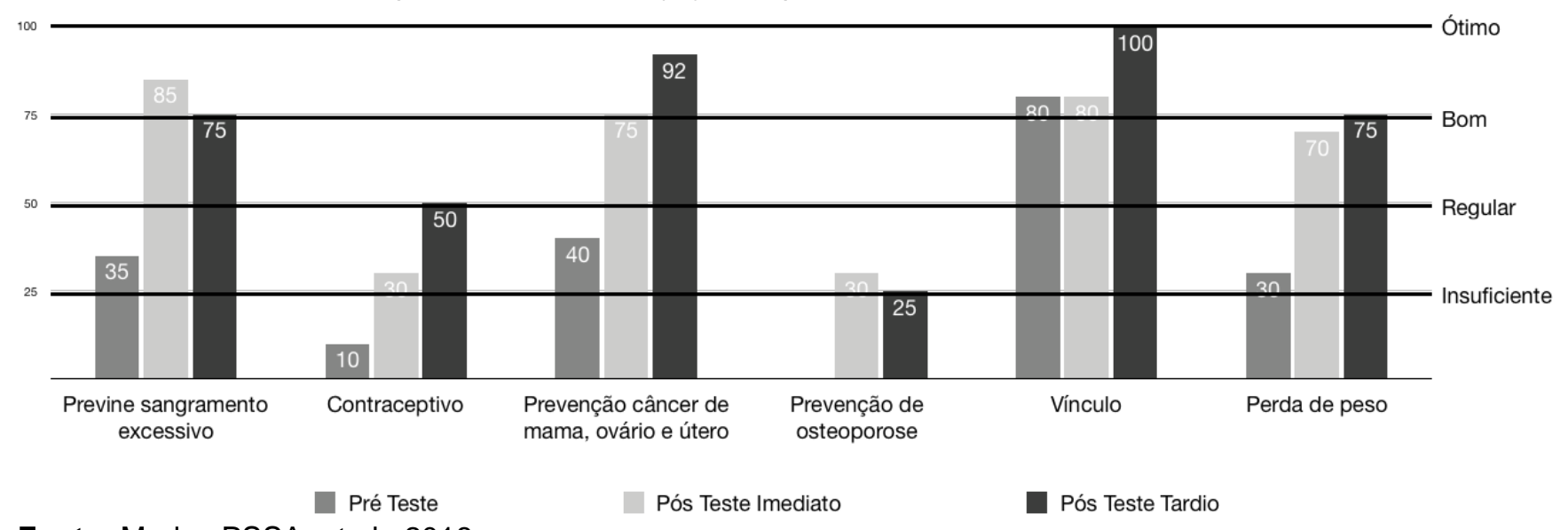

Fonte: Modes PSSA, et al., 2018.

\section{DISCUSSÃO}

Neste estudo, a maioria das gestantes participantes apresentou nível de conhecimento insuficiente ou regular sobre o aleitamento materno antes da aplicação da intervenção (pré-teste). Contudo, logo após a mesma, grande parte delas exibiu conhecimento bom e ótimo, tanto no pós-teste imediato, quanto no tardio, mostrando a efetividade da oficina. Ainda, o conhecimento e o número de acertos no pós-teste imediato e no tardio em alguns itens foram semelhantes, com destacada melhora no teste aplicado a longo prazo, indicando que o efeito da intervenção se manteve, garantindo a sustentabilidade dos saberes no intervalo de tempo estabelecido.

Estudo com puérperas no pós-parto mediato (1aa $\left.10^{\circ} \mathrm{dia}\right)$, identificou maiores escores de autoeficácia à prática do aleitamento materno entre aquelas que realizaram seis ou mais consultas de pré-natal, evidenciando que as mulheres que receberam mais informações sobre o aleitamento materno têm maiores chances de mantê-lo de maneira exclusiva até o sexto mês de vida do bebê e realizar escolhas mais conscientes (SILVA MFFS, et al., 2018). Esses resultados, reforçam a importância da informação para a manutenção da prática do AM.

Contudo, em muitas localidades brasileiras, o acesso da gestante à informação ainda é escasso, a exemplo de pesquisa realizada em hospital universitário de Cuiabá-MT, em que apenas 48,9\% das mães que tiveram seus partos neste hospital, referiram ter recebido orientação de profissional de saúde sobre o aleitamento materno exclusivo (AME) durante o acompanhamento de pré-natal e apenas $20,3 \%$ relataram participação em alguma prática educativa como rodas de conversa e palestras (BARBOSA LN, et al., 2015).

Assim como no presente estudo, pesquisa realizada na Índia com objetivo de avaliar o conhecimento e a atitude de mães no puerpério em relação à amamentação e práticas de alimentação infantil, também identificou conhecimento deficiente sobre o aleitamento materno, sendo que $21,3 \%$ das participantes conheciam os benefícios do aleitamento materno, e apenas 6,5\% da população pesquisada realizou aleitamento materno na primeira hora de vida do bebê. Os investigadores concluíram que há necessidade de maior conscientização da população sobre a importância desta prática (BASHIR A, et al., 2018).

Sabe-se que a recomendação do início da amamentação ainda na sala de parto, na primeira hora de vida da criança, propicia inúmeros benefícios, dentre eles, a construção e fortalecimento de vínculo mãe filho, através do contato pele a pele, que estimula a ocitocina a liberar o primeiro leite materno (colostro); favorece a adaptação do recém-nascido à vida extrauterina, auxiliando na autorregularão de seus sinais vitais (MINISTÉRIO DA SAÚDE, 2015a; LOPES JMA, et al., 2018; ABDALA LG e CUNHA MLC, 2018; UNICEF, 2018); proporciona aquecimento do neonato; previne hemorragias pós-parto (MINISTÉRIO DA SAÚDE, 2015a) e; contribui na prevenção do desmame precoce (LOPES JMA, et al., 2018; UNICEF, 2018a). 
Apesar do Ministério da Saúde (MS) (2015a) recomendar a adoção do AME em livre demanda nos primeiros 6 meses de vida da criança, quase metade das gestantes participantes deste estudo não possuíam esse conhecimento antes da realização da intervenção. O que reforça a relevância de esclarecer e reforçar às gestantes em todo o período gestacional e puerperal dentre outros aspectos, sobre o período e duração do AME.

São vários aspectos a serem considerados na técnica de amamentação que contribuem para o sucesso e manutenção do AME e para prevenção de problemas mamários. Nesta pesquisa, as participantes mostraram conhecimento insuficiente em alguns deles e, mesmo após a intervenção, ainda se mantiveram como regulares, indicando a necessidade de reforço de orientações por parte dos profissionais da unidade de saúde.

Nesse sentido, investigação evidenciou que o baixo conhecimento a respeito do posicionamento adequado do bebê para mamar e mamas endurecidas são fatores que contribuem como principais empecilhos para a amamentação, principalmente entre aquelas mulheres que estão vivenciando a gestação pela primeira vez. Diante deste e de outros empecilhos é necessário elaborar intervenções efetivas e métodos estratégicos para auxiliar as mulheres neste processo (SILVA AM, et al., 2018).

O aparecimento de problemas mamários como ingurgitamento e lesões mamilares, desencadeados pela pega inadequada e/ou posição para amamentar desconfortável, podem surgir nas primeiras semanas do pós-parto, sendo este um fator preditivo para interrupção da prática do aleitamento materno (ROSA JBS e DELGADO SE, 2017; BARBOSA GEF, et al., 2017) e a ocorrência do desmame precoce (SOUSA JR, et al., 2018). Além disso, é um fator de risco para a redução da produção de leite, porém pode ser evitável por meio de aconselhamento adequado por parte dos profissionais (PÉREZ-ESCAMILLA R, 2017).

A orientação quanto a técnica correta da ordenha manual, armazenamento e administração do leite materno é de extrema relevância, e devem ser trabalhadas com a gestante durante o pré-natal para oferecer conhecimento sobre como manter o AME, prevenindo ansiedade e preocupação materna (MINISTÉRIO DA SAÚDE, 2015b). Os achados deste estudo demonstraram que as gestantes partiram de um conhecimento insuficiente para bom e ótimo, demonstrando que é possível preparar essa futura mãe para seu retorno ao trabalho, ou caso precise numa eventualidade, que outra pessoa oferte o leite materno à criança.

No que se refere aos benefícios que o aleitamento proporciona ao binômio mãe-bebê, as participantes demonstraram conhecimento frágil naqueles relacionados à mulher e em outros que são desconhecidos ou pouco citados, merecendo maior divulgação por parte dos profissionais durante o acompanhamento da gestação.

Já está bem sedimentado pela literatura os benefícios da prática do aleitamento materno para a mulher, dentre os quais destacam-se, a proteção contra o câncer de mama (BRITO JCD, 2018); de ovário (FERREIRA CKM, et al., 2017; SANTOS GCP et al., 2017; SANTOS VR, et al., 2016); contraceptivo no período puerperal e favorece a perda de peso após o parto (MINISTÉRIO DA SAÚDE, 2015a; UNICEF, 2018); além de promoção da troca de afeto entre mãe e filho e criação de vínculo (BASHIR A, et al., 2018; UNICEF, 2018), reduzindo os custos para as famílias e a sociedade.

Reforçar sobre os benefícios não comumente conhecidos, a exemplo de ser usado como um método anticoncepcional, foi identificado em estudo realizado com 278 puérperas internadas em alojamento conjunto em maternidade do município de Fortaleza, CE, a fim de verificar o conhecimento do método anticoncepcional da lactação com amenorreia, em que apenas $131(47,1 \%)$ mulheres haviam ouvido falar sobre tal método anticoncepcional, e destas, 56 (42,7\%) tiveram acesso ao conhecimento no pré-natal.

No entanto, $94(71,6 \%)$ das participantes do estudo desacreditavam sobre sua eficácia, 100 (76,3\%) desconheciam os critérios para uso seguro e 71 (54,1\%) não foram orientadas por profissionais da saúde em nenhuma oportunidade de contato (MORAES JL, 2015). Por sua vez, outro estudo desenvolvido com puérperas demonstrou que para elas o único benefício para a mulher que amamenta é a perda de peso no pós-parto (ROSA JBS e DELGADO SE, 2017). 
Os resultados da presente pesquisa reafirmam que ainda há um longo caminho a ser percorrido com o intuito de ultrapassar as barreiras existentes para uma amamentação eficaz. Sabe-se que uma das estratégias para melhorar a prevalência do AME é a educação em saúde, que se desenvolvida durante a gravidez, período considerado ideal para aquisição de novos conhecimentos e encorajar a prática da amamentação, pode oferecer informações e sensibilizar sobre a importância do AM (TEIXEIRA FV, et al., 2016). Autores afirmam que as ações educativas realizadas no período gestacional e pós-natal, podem corrigir os erros e reduzir o desmame precoce (ROSA JBS e DELGADO SE, 2017).

Todavia, recomenda-se que durante a prática educativa os profissionais de saúde levem em consideração o contexto sociocultural de cada gestante/nutriz, não apenas disseminem informações esperando que as mulheres se motivem a amamentar e obtenham sucesso com o mesmo. É preciso que haja acolhimento, escuta ativa, apoio emocional, aproximação, criação de vínculo de confiança e incentivo, visando a autonomia da mulher, a fim de que seja responsável pelo cuidado e favoreça 0 alcance de melhores índices da prática de aleitamento materno (COSTA EFG, et al., 2018).

Bashir A, et al. (2018) recomendam que os profissionais de saúde, em especial enfermeiros, sejam treinados para conscientizar e adotar boas práticas ao aleitamento materno entre as mulheres. $O$ destaque dado ao profissional enfermeiro se justifica em função de que sua formação está sustentada no processo de cuidar e no preparo para o manejo clínico do aleitamento materno. Sendo assim, este profissional tem potencial para exercer papel de facilitador da prática ao aleitamento materno, fomentando a autonomia materna (COSTA EFG, et al., 2018).

Dentre as limitações da pesquisa, destacam-se o tamanho pequeno da amostra e restrita a uma única unidade de saúde da família, além daquelas relativas ao próprio método de pesquisa, como ausência de grupo controle e de follow-up. Sugere-se o desenvolvimento de novos estudos com esse tipo de intervenção, com a participação de um número maior de gestantes e em diferentes contextos, a fim de verificar a sua efetividade.

\section{CONSIDERAÇÕES FINAIS}

Diante dos resultados obtidos nesta pesquisa de intervenção, observou-se que as gestantes demonstraram pouco conhecimento sobre alguns aspectos da amamentação, como o aleitamento na primeira hora de vida do RN, posição e pega corretas, causas do ingurgitamento mamário, benefícios da amamentação para contracepção e prevenção da osteoporose, mas que após a oficina educativa houve a ampliação de seus conhecimentos nestes assuntos, demonstrando a relevância de oficinas educativas para apoiar, promover e proteger o AM.

\section{REFERÊNCIAS}

1. ABDALA LG, CUNHA MLC. Contato pele a pele entre mãe e recém-nascido e amamentação na primeira hora de vida. Clin Biomed Res, 2018; 38(4):356-360 .

2. BARBOSA LN, et al. Prevalência de práticas educativas acerca do aleitamento materno exclusivo (AME) em Cuiabá - MT. Esc Anna Nery, 2015; 19(1):147-153.

3. BARBOSA GEF, et al. Initial breastfeeding difficulties and association with breast disorders among portpartum women. Rev Paul Pediatr., 2017; 35(3):265-272.

4. BASHIR A, et al. Knowledge, attitude, and practices of postnatal mothers regarding breastfeeding:A cross-sectional study. International Journal of Medical Science and Public Health, 2018; 7(Issue 9): 725-730.

5. BLANCO e SILVA F, et al. Intervenção educativa com mães jovens: aquisição de saberes sobre cuidados da criança. Acta Paul Enferm., 2018; 31(1):32-38.

6. BONFIM ES, et al. Atuação do enfermeiro acerca das práticas educativas na Estratégia De Saúde da Família. Rev enferm UFPE on line., Recife, 2017; 11(Supl. 3):1398-1402.

7. BRITO JCD. O aleitamento materno como forma de prevenção ao câncer de mama. Revista Científica Multidisciplinar Núcleo do Conhecimento, 2018; 14(03): 61-81.

8. CONSELHO NACIONAL DE SAÚDE. Decreto-lei $\mathrm{n}^{\circ}$ 466, de 12 de dezembro de 2012. Dispõe do respeito pela dignidade humana e pela especial proteção devida aos participantes das pesquisas científicas envolvendo seres humanos. Diário Oficial da União, Brasília - DF, 12 de dezembro de 2012. 
9. CORDONI JUNIOR L. Elaboração e avaliação de projetos em saúde coletiva. Londrina: Eduel; $2013 ;$ p. 12.

10. COSTA EFG, et al. Atuação do enfermeiro no manejo clínico da amamentação: estratégias para o aleitamento materno. J. res.: fundam. care. Online, 2018; 10(1): 217-22.

11. FERREIRA CKM, et al. Composição do leite humano e sua relação com a nutrição adequada à Recém - Nascidos Pré-Termos. Rev. Temas em Saúde, João Pessoa, 2017; 17(1): 118 -146.

12. LOPES JMA, et al. Nascimento seguro. Sociedade Brasileira de Pediatria. 2018; abr., n.3: 1-16.

13. MENDES R, et al. Pesquisa-intervenção em promoção da saúde: desafios metodológicos de pesquisar "com". Ciência \& Saúde Coletiva, 2016; 21(6): 1737-1745.

14. MINISTÉRIO DA SAÚDE. Saúde da Criança: Aleitamento Materno e Alimentação Complementar. Caderno de Atenção Básica, no 23. 2.ed. Ministério da Saúde: Brasília - DF; 2015a; 184 p.

15. MINISTÉRIO DA SAÚDE. Guia para implantação de salas de apoio à amamentação para a mulher trabalhadora. Ministério da Saúde: Brasília - DF; 2015b; 16 p.

16. MORAES JL. Conhecimento de puérperas acerca do método anticoncepcional da lactação com amenorreia. Chía, Colombia, 2015; 15(4): 475-485.

17. OLIVEIRA MF, FANARO GB. Aleitamento materno na prevenção de sobrepeso, obesidade infantil e alergias. Rev Bras Nutr Clin, 2015; 30(3): 216-226.

18. PÉREZ-ESCAMILLA R. Breastfeeding in Brazil: major progress, but still a long way to go. J Pediatr (Rio Janeiro), 2017; 93:107-110.

19. QUENTAL LLC, et al. Práticas educativas com gestantes na atenção primária à saúde. Rev enferm UFPE on line., Recife, 2017; 11(Supl. 12): 5370-5381.

20. RICCI APA, et al. Infecções sexualmente transmissíveis na gestação: educação em saúde como estratégia de prevenção na atenção básica . Braz. J. Hea. Rev., Curitiba, 2019; 2(1): 565-570.

21. ROSA JBS, DELGADO SE. Postpartum women's knowledge about breastfeeding and introduction of other foods. Rev Bras Promoç Saúde, Fortaleza, 2017; 30(4): 1-9.

22. SANTOS VR, et al. Aleitamento materno: Benefícios enquanto fator na prevenção de doenças no neonato. Revista científica interdisciplinar, 2016; 1(01); art. no 05: 47 - 60 .

23. SANTOS GCP, et al. Os benefícios da amamentação para a saúde da mulher. Revista Saúde em Foco, 2017; ed. 9: 225-228.

24. SILVA AM, et al. Aleitamento materno exclusivo: empecilhos apresentados por primíparas. Rev enferm UFPE on line., Recife, 2018; dez,12(12): 3205-3211.

25. SILVA MFFS, et al. Autoeficácia em amamentação e fatores interligados. Rev Rene. Rev Rene. 2018; 19(e3175): 17.

26. SOUSA JR, et al. Aspectos envolvidos na interrupção precoce do aleitamento materno exclusivo: revisão integrativa. Braz. J. Surg. Clin. Res., 2018; 24(3): 126-129.

27. TEIXEIRA FV, et al. Oficinas educativas para um grupo de gestantes acerca do período gravídico. SANARE, Sobral, 2016; 15(01):119-125.

28. UNICEF, WHO. Capture the Moment - Early initiation of breastfeeding: The best start for every newborn. New York: UNICEF, 2018; $44 \mathrm{p}$.

29. VARGAS GS, et al. Atuação dos profissionais de saúde da Estratégia Saúde da Família: promoção da prática do aleitamento materno. Revista Baiana de Enfermagem, Salvador, 2016;30(2):1-9.

30. VIEIRA F, et al. Educação em saúde para promoção do aleitamento materno: relato de um projeto de extensão. Rev Enferm UFPI, 2016; 5(2):80-83. 